The importance of the observations lies in the fact that a service offered to all is not being taken up evenly across the whole community.

It is also clear that many children from all ethnic groups are not receiving immunisations at the recommended ages. Delay in taking immunisation might occur for a number of reasons such as frequent change of address, the child may be unwell or considered unfit for immunisation by the doctor or health visitor on the scheduled day, and there may be poor understanding and poor motivation to accept immunisation on the part of the parents or of the health service staff. This is unfortunate when $33 \%$ of notifications for whooping cough and $28 \%$ of notifications for measles in Bradford are for children aged 24 months or less.

It is not possible to quantify how many of the differences are related to ethnic group as opposed to factors such as social class, place of residence, or the practices of local health professionals. Further research using the same life table method could clarify this and allow better targeting of health care.

It is also suggested that a study should be made of the Indian community to identify those characteristics that encourage their desirable pattern of immunisation uptake so that these can be encouraged in other groups.

Finally, it is suggested that the graphical method of presenting life table data on immunisation be developed as a form of understandable feedback to those directly working in immunisation programmes.

We thank Dr R Turner, Yorkshire Regional Health Authority, for his help in preparing the graphs, and Dr D Clayden, department of community medicine, University of Leeds, for his help with statistics.

\section{References}

1 Davison AG, Hildrey ACC, Floyer MA. Health problems of ethnic minorities. $\mathrm{Br} \mathrm{Med} \mathcal{F} 1983 ; 286$ :1575-6.

2 Marks JS. Risk factors associated with failure to receive vaccinations. Pediatrics 1979;64:303-9.

3 Noah ND. Vaccination today. Br $\mathcal{F}$ Hosp Med 1980;24:533-6.

4 Clarke SJ. Whooping cough vaccination: some reasons for non-completion. f Adv Nurs 1980;5:313-9.

${ }^{5}$ Smith T. Our national resistance to immunization. The Health Services 11 March 1983:12.

- Cox PR. Life tables: the measure of mortality. Population Trends 1. London: HMSO, 1975 (OPCS).

7 Cox PR. Life tables: (2) wider applications. Population Trends 2. London: HMSO, 1976 (OPCS.)

${ }^{8}$ Siegel S. Non-parametric statistics for the behavioural sciences. Maidenhead, Berks: McGraw Hill Book Co (UK) Ltd, 1956.

(Accepted 9 December 1983)

\title{
Four years' experience with a mobile gammacamera service
}

\author{
M V MERRICK, V F SMITH
}

Mobile gammacameras and mobile computed $x$ ray transmission tomographic units are widely available in the United States. A commercial mobile computed $x$ ray transmission tomographic unit has recently begun operating in the United Kingdom. Little has been written about these services; their continued survival and expansion are in themselves evidence for their commercial viability but do not necessarily prove that such a service is of benefit to the National Health Service.

The Borders, Fife, and Lothian health boards are jointly responsible for a population of about 1.25 million spread over about 3000 square miles. Specialised services are largely concentrated in the city of Edinburgh, which covers one third of the total population but only $2 \%$ of the land area, and one hospital is designated as the regional centre for a number of specialties including nuclear medicine. By 1976 it was evident that the existing facilities for nuclear imaging in the south east of Scotland were approaching saturation point, and provision for growth had to be considered. A survey of users indicated a large discrepancy between hospitals with facilities on site and those without: even after taking into account referrals from general medical and surgical units, and excluding those from specialised units such as oncology, there was a fivefold difference in referral rate. In 1977 therefore, it was decided to establish an experimental mobile gammacamera service to study both practical problems and their economic consequences.

Medical Radioisotope Department, Western General Hospital, Edinburgh EH4 2XU

M V MERRICK, FRCR, consultant in nuclear medicine

V F SMITH, DSR, superintendent radiographer

Correspondence to: Dr M V Merrick.
The service opened in January 1980 , and we discuss the experience gained and the conclusions reached after almost four years of experience.

\section{Choice of hospital}

The region served contains 15 general hospitals without nuclear imaging facilities. Three further general hospitals, including the base hospital, had nuclear imaging facilities, and these were subsequently installed at one of the other hospitals. The region also contains many specialised hospitals (orthopaedic, paediatric, geriatric, psychiatric, etc) that were not considered for the service, as well as numerous smaller hospitals. The distance by road from the general hospitals without facilities for nuclear medicine to the regional centre ranged from less than half a mile to over 30 miles.

To provide a useful service one visit a week was considered to be the minimum and two visits a week optimum, which would leave a maximum of four days between visits. Many patients with suspected pulmonary emboli can be given heparin for this period, and lung scintigraphy could then be used to decide whether or not to proceed to long term oral anticoagulants.

As it was clearly impossible for a single mobile camera to visit all the hospitals in the area, precedence was given to the larger and more distant hospitals, provided that they were able to accommodate the camera. This required a room not less than $3 \mathrm{~m}^{2}\left(10 \mathrm{ft}^{2}\right)$, with a door large enough to allow access for a patient on a trolley and a floor strong enough to withstand the weight of the gammacamera (about one tonne). A single $13 \mathrm{amp}$ power point was the only service required: no special radiation shielding is required as the scattered radiation from the procedures to be performed is much less than in radiography and 
is not dissimilar to normal background. One hospital was excluded because the floors in its old buildings would not support the weight of the camera. In some others a suitable room was available only on a particular day of the week when not used by outpatient clinics. Even with these constraints the number of potential sites was more than could be visited. Initially it was decided to spread the net as widely as possible and visit five different hospitals each on one day a week. Four were near the periphery of the area served and therefore gave the greatest saving in ambulance journeys. The fifth hospital was the largest of the general hospitals within the city of Edinburgh not to have nuclear imaging facilities; it contained 366 beds and was situated about $6 \mathrm{~km}$ ( 4 miles) from the regional centre. The other hospitals chosen were $56 \mathrm{~km}$ ( $35 \mathrm{miles})$ distant ( 220 beds), $40 \mathrm{~km}$ ( 25 miles) ( 460 beds), $32 \mathrm{~km}$ ( 20 miles) (328 beds on two sites about one mile apart), and $24 \mathrm{~km}$ (15 miles) (563 beds). The timetable was organised to take into account local constraints on availability of a room, and also as far as possible to minimise the number of loading and unloading operations of the gammacamera. Thus on some days the camera is not returned to the base hospital but is deposited at the hospital where it is next to be used.

\section{Organisation}

Three types of service were considered: firstly, a scheduled service visiting predetermined hospitals on a regular rota; secondly a call out service in which the camera was sent out only when it was needed at a particular hospital; and thirdly a combination of the two. The third option was rejected as giving the worst of all combinations-namely, a scheduled service with frequent but erratic interruptions compounded by a slow and unreliable emergency service. Most nuclear imaging investigations are required urgently-that is, within one or two days of the request-but only rarely are investigations required on an emergency basis-that is, within hours. The commonest example of an investigation required within hours is lung perfusion scintigraphy to confirm or refute a clinical suspicion of a pulmonary embolus. The lack of an emergency service for lung scintigraphy (unless the patient was transported to the base hospital) was recognised as a deficiency of a wholly scheduled service, but one that could be.remedied only by operating with a high and probably uneconomic staffing level. An emergency call out service was therefore excluded on these grounds.

Each hospital is responsible for arranging its own appointments. In most cases this is performed through the $x$ ray department reception, but in one case it was more convenient to use the outpatient appointment system. In practice, provided that everyone concerned was clearly informed of the local arrangement, both systems worked satisfactorily.

Initially, up to 13 examinations were performed a day. In view of the travelling time of the staff, who drive out from the base hospital every day with the radiopharmaceuticals and return every evening with the results for reporting, this proved excessive. The prebooked list is now limited to allow sufficient time to accommodate any urgent requests arising during the visit. A "points" system is used to take account of the different time required by various investigations. Precedence is given to inpatients and infirm outpatients who might be distressed by a long journey to the base hospital. Fit outpatients who cannot be accommodated are given appointments at the base hospital. Early in the afternoon of the day preceding the scheduled visit (or late on Friday afternoon in the case of Monday visits) the list is obtained by the superintendent radiographer, who, after consultation with the consultant in nuclear medicine (if necessary), is responsible for ordering the appropriate radiopharmaceuticals from the area radiopharmacy. Additional technetium macroaggregate is always carried so that unbooked urgent investigations can be undertaken (one or two on most days).

Radiopharmaceutical injections are administered by a radio- grapher who has previously been trained and approved by the consultant in charge of the service. If any other drugs are required-for example, diuretics for renal investigations-these are administered by one of the local medical staff designated in advance.

\section{Transport}

Two alternatives were considered: firstly, a mobile fully equipped examination room to be parked in the hospital grounds, similar to a mass miniature $x$ ray unit, and, secondly, a van modified to carry a mobile gammacamera, which would then be unloaded and operated within the hospital. The use of a mobile room would eliminate the need to load and unload the camera or to allocate a room, but this option was rejected because of the higher capital and running costs (more than four times those of a van). The driver of a suitable vehicle would have required a heavy goods vehicle licence; there can be few radiographers who hold this qualification, and at the time of inception of the service it was not thought to justify a full time driver.

A Bedford van (35 cwt cab and chassis) was adapted. ${ }^{1}$ In practice, loading the equipment into the van and fixing it into position proved difficult and heavy work. When the van has to be replaced a larger vehicle, of nominal 3.5 tonne capacity, equipped with a tail lift will be purchased and adapted. Any further scheme of this nature should use the larger vehicle and not try to use one that is too small.

\section{Gammacamera}

An Elscint Dymax MB mobile gammacamera with Dycomette $\mathrm{XL}$ data processor was purchased for the evaluation. The camera has continued to maintain its specified level of performance. Down time because of faults developing in the equipment has been little higher than that in fixed equipment at the base hospital (on average about one day a fortnight).

\section{Staffing}

There is no qualification for technologists in nuclear medicine in the United Kingdom, and the work may be performed either by a radiographer or by a medical physics technician. A postgraduate diploma is available for radiographers, but relatively few hold it. Medical physics technicians have no training in patient care, no registerable qualifications, and the formal training that they are required to undergo is often irrelevant to the work they actually perform. It was therefore thought unwise to staff the service completely with medical physics technicians, particularly as they would have to work largely unsupervised. On the other hand, few radiographers have sufficient knowledge of electronics to trace and possibly correct any faults. We therefore employed one radiographer, graded superintendent 4 by analogy with the mass miniature radiography service, and one medical physics technician graded MPT 3.

There was at any one time work for only one skilled person, though two pairs of hands were always needed, and initially the service had to be suspended whenever either member of staff was absent. Subsequently we appointed a driver who, in addition to driving and unloading the van, was able to provide general help by fetching patients, taking films to the dark room, supporting patients, etc.

The few breakdowns were insufficient to justify employing a medical physics technician for fault finding and servicing. When the original technician resigned after one and a half years no suitable replacement could be found, and a second radiographer was appointed. The camera is always accompanied by two people, normally the driver and one of the radiographers; 
only when the driver is on leave do both radiographers work together. This has proved to be a flexible and efficient arrangement, as the second radiographer is able to provide additional help in the main department.

\section{Services provided}

So far as possible it was the intention to provide the same investigations from the mobile gammacamera as were provided at the regional centre. On the other hand, certain constraints were imposed by the mobile gammacameras available at the time the service was started, the major being their relatively small field of view. The one purchased has a field of view of $30 \mathrm{~cm}$ diameter, which, though adequate for most purposes, is suboptimal for skeletal imaging. It was therefore decided that skeletal scintigraphy would not be performed on the mobile camera except in patients who were too ill or in too much pain to be moved. As the commonest indication for skeletal scintigraphy is the preoperative detection of occult metastases, and these occur mainly in ambulant outpatients, this was not a major limitation. This field is also slightly too small to include the whole or both lungs in men of average to large size, and as the only available diverging collimator had an unacceptably low sensitivity it is necessary to obtain a separate posterior and anterior view of each lung in larger patients. The field is adequate for most female lungs and most renal and hepatic investigations, though separate left and right posterior views of the liver are occasionally required.

Another limitation was the lack of a pinhole collimator for thyroid imaging; a suitable collimator has now been constructed in the hospital workshop.

All other investigations available at the regional centre are also available on the mobile service. The limited data processing facility available on the mobile camera has proved adequate for most purposes. It cannot, however, perform phase analysis of gated cardiac studies, but data collected on the mobile unit are transferred to one of the computers in the base hospital for subsequent analysis.

${ }^{9} \mathrm{~m}$ Tc radiopharmaceuticals are used for most investigations, ${ }^{133} \mathrm{Xe}$ being used for lung ventilation studies. Investigations requiring other isotopes such as ${ }^{111} \mathrm{In}$ or ${ }^{131} \mathrm{I}$ are rare and are undertaken at the base hospital. Procedures such as white cell labelling are in any case too protracted to be feasible with a mobile service.

All radiopharmaceuticals are dispensed from the area radiopharmacy and packed in a container designed to comply with the various legal requirements for transport of radioactive substances by road. Empty vials, used syringes, etc are returned to the base hospital for disposal, and each of the hospitals visited is licensed for disposal of radioactive excreta. The appropriate sections of the code of practice are at all times strictly observed.

\section{Experience gained}

The average number of investigations undertaken at each visit varied from four to seven, the lowest number being at the nearest hospital, where the service was terminated after a few months. Both here and at a second hospital close to the base hospital it was found that the inconvenience of waiting a few days until the next visit outweighed the discomfort of a short ambulance journey to the base hospital. For the past two years only three hospitals have been visited, one twice a week, one twice a week on two weeks a month and once on the other two weeks, and the other once a week for three weeks out of four and twice in the fourth week. It is noticeable that the average number of investigations undertaken at each visit fell at the hospital receiving two visits a week (hospital 1 ) from $7 \cdot 4$ to $4 \cdot 4$, indicating that the potential workload does not rise indefinitely (table I). Table II shows the distribution of workload, which varied little among the various hospitals. The small number of cardiac investigations performed makes it clear that the potential for nuclear cardiology is not yet fully appreciated in the United Kingdom, and that this investigation is underutilised. ${ }^{2}$

To obtain some idea of the value of the service we conducted a prospective questionnaire over three months. Table III shows

TABLE I-Mean No of scintigraphic examinations undertaken on each visit of the mobile gammacamera to five hospitals

\begin{tabular}{ccccc}
\hline Hospital & 1980 & 1981 & 1982 & 1983 \\
\hline $1^{*}$ & $5 \cdot 5$ & $7 \cdot 4$ & $4 \cdot 4$ & $4 \cdot 1$ \\
2 & 6.5 & $5 \cdot 8$ & $7 \cdot 0$ & $5 \cdot 4$ \\
3 & 5.9 & 6.5 & 6.0 & 6.1 \\
4 & 3.9 & 4.2 & &
\end{tabular}

*Based on two sites about one mile apart.

\begin{tabular}{lc}
$\begin{array}{l}\text { TABLE II-Distribution of } \\
\text { investigations requested }\end{array}$ \\
\hline & Mean \% \\
\hline Cerebral & 35.4 \\
Liver (colloid) & 23.5 \\
Renal & 20.4 \\
Lung & $11 \cdot 1$ \\
Skeletal & $5 \cdot 6$ \\
Cardiac & $2 \cdot 1$ \\
Meckels & $0 \cdot 1$ \\
Thyroid & 1.8 \\
\hline
\end{tabular}

TABLE III-Effect of scintigraphy on diagnosis and management

\begin{tabular}{lrr}
\hline & No & $\%$ \\
\hline \multicolumn{1}{c}{ Diagnosis } & 15 & 9 \\
New diagnosis & 15 & 9 \\
$\begin{array}{l}\text { Diagnosis changed } \\
\text { Provisional diagnosis confirmed }\end{array}$ & 76 & 44 \\
Scintigraphy performed for assessment & 65 & 38 \\
& & \\
Stay in hospital shortened & 15 & 9 \\
$\begin{array}{l}\text { Treatment changed } \\
\text { Inappropriate treatment stopped }\end{array}$ & 20 & 12 \\
Choice of appropriate treatment expedited & 58 & 34 \\
Other investigations were not performed & 74 & 43 \\
\hline
\end{tabular}

TABLE IV-Details of investigations that would have been performed in the absence of scintigraphy

\begin{tabular}{lr}
\hline \multicolumn{1}{c}{ Investigation } & No \\
\hline Excretion urography & 20 \\
Micturating cystourethrogram & 13 \\
Computed tomography & 12 \\
Biopsy & 8 \\
Angiography & 5 \\
Ultrasound & 4 \\
Lumbar puncture & 4 \\
Laparotomy & 3 \\
Endoscopy & 2 \\
Venography & 1 \\
Cardiac catheter & 1 \\
Not specified & 1 \\
\hline
\end{tabular}

the effect of scintigraphy on diagnosis and management, and table IV gives details of investigations that would have been performed if scintigraphy had not been available. Furthermore, when asked retrospectively what action would have been taken if the mobile service had not been available the referring consultants estimated that 120 out of 157 patients would have been sent to the base hospital for scintigraphy and 37 would have had an alternative investigation performed locally. In addition doctors at one hospital volunteered the 
information that 14 patients would have been unfit to travel; this suggests an underestimate of the number of patients in this category.

As additional imaging and data processing facilities and the staff to operate them were considered necessary to take account of natural growth of the service, and as there was no appreciable difference between the capital cost and service contract of a fixed installation and of a mobile one, the additional costs of the mobile service were the purchase of the van and the revenue costs of the van and its driver. If we assume that the capital cost of the van is written off linearly over four years (in accordance with health board policy to replace vehicles after four years), the annual running costs amount to $£ 9300$, or about $£ 180$ a week. If, in the absence of a mobile service, each of the hospitals served were responsible for one additional ambulance journey a week (a conservative estimate), the cost to the NHS would be about $£ 190$ a week.

Other potential savings can be identified as a result of the mobile service.

(1) Several patients would otherwise have had other investigations that are no less expensive, and in many cases rather more expensive, than scintigraphy performed on a high throughput machine.

(2) In a comparatively small number (about $10 \%$ ) of patients stay in hospital is shortened as a result of the investigation (table III).

(3) When a patient is to be transported to another hospital for investigation, the time required to organise transport and to find a suitable escort may take up to one hour of a ward sister's time. In addition, an escort can be provided only by depriving a ward of a nurse for at least half a day.
(4) The reduction in inappropriate treatments and avoidance of laparotomies also makes some contribution to the net saving.

\section{Conclusions}

The concept of a mobile gammacamera service has been shown to work efficiently in an area of low population densitynamely, the south east of Scotland, where a population of about one and a quarter million is spread unevenly over some 3000 square miles. Experience suggests, however, that such a service would not be cost effective in an urban area of high population density.

We wish to thank the many colleagues whose enthusiasm and support have made this project possible, and especially to the chief administrative medical officer of the Lothian Health Board (Dr C Brough). The project was funded initially by the Scottish Home and Health Department, to whom we express our thanks.

\section{References}

${ }^{1}$ McKillop JH, Tweddel AC. Physicians' attitudes to nuclear cardiology. Nuclear Medicine Communications 1983;4:343-7.

'Smith MA, Merrick MV, Storjohann VF, Wong AJ. A transportable gamma camera service: initial technical results. $B r \mathcal{F}$ Radiol $1981 ; 54$ : 808-12.

(Accepted 4 fanuary 1984)
What is the treatment for polymyalgia rheumatica and temporal arteritis?

In both polymyalgia rheumatica and temporal arteritis so dramatic is the improvement of symptoms with prednisolone that this drug not only produces "the grateful patient syndrome" but also has been used as a diagnostic test for these conditions. ${ }^{1}$ Certainly, if visual symptoms are associated with the onset of temporal arteritis delay in administering steroids may result in sudden loss of sight from retinal artery involvement. ${ }^{2}$ The starting dose varies according to different authorities, but clinical experience has shown that beginning with $30-60 \mathrm{mg}$ of prednisolone daily (depending on the size of the patient and using the higher dose if vision is threatened) the treatment may be gradually reduced after three to four weeks to the optimum level according to the degree of symptom relief and the reduction in the erythrocyte sedimentation rate. This is particularly important in elderly patients, the group most commonly affected by these conditions, when steroid treatment is most likely to be associated with its own severe and well known complications. The differential diagnosis of polymyalgia includes the generalised aches and pains sometimes associated with osteomalacia. This condition is also more common in the elderly and quickly responds to treatment with calcium and vitamin D.-BRIAN LIVESLEY, consultant physician in geriatric medicine, London.

' Bird HA. Polymyalgia rheumatica and temporal arteritis. In: Wright V, ed. Bone and joint disease in the elderly. London: Churchill Livingstone, 1983:73-5.
${ }^{2}$ Russell RWR. Giant-cell arteritis: a review of 35 cases. $Q \mathcal{F}$ Med 1959;28:471-89.

Armed with a family history covering two previous generations and knowledge of a patient's blood group, what predictions of life span and morbidity can be made?

The span of life is determined by many environmental and genetic influences, and a simple inheritance of life expectancy or a straightforward relation between lifespan and blood groups would not be expected. Any obvious family history of genetic disease will have a direct bearing on the lifespan of the offspring, and it may be possible to determine the probability of living a normal life expectancy. In the absence of such specific diseases there is a correlation between the life expectancy of parents and their children. Pearl and Pearl showed that the average age of parents and grandparents in nonagenarians was greater than that for a control population..$^{1}$ As women tend to live longer than men, an increased paternal age is likely to have a greater importance than increased maternal age. With the present state of knowledge, however, it is not possible to make accurate predictions of life expectancy for an individual. There have been some associations between blood groups and increased or decreased survival. For example, Beller and Palmore in a study of nonagenarians in Turkey found an increase in blood group $\mathrm{P}_{2}$ and Le (a-b-). ${ }^{2} \mathrm{~A}$ link between HLA and longevity might be expected if there were an immunological basis to aging. Greenberg and Yunis have shown that HLA A1-B8, which is associated with autoimmune disease, is also associated with decreased survival in women. ${ }^{3}-$ MICHAEL A PATTON, senior registrar and MICHAEL BARRAITSER, consultant geneticist.

1 Pearl IR, Pearl RD. The ancestry of the long-lived. Baltimore: Johns Hopkins University Press, 1934.

'Beller S, Palmore E. Longevity in Turkey. Gerontology 1974:14:373-6.

Greenberg LJ, Yunis EJ. Genetic control of autoimmune disease and immune responsiveness and the relationship to aging. Birth Defects Original Articles Series 1978;XIV:249-60.

Is there any evidence for a beneficial effect of topical BCG vaccine after mastectomy for breast cancer?

Although topical BCG vaccination has been used in treating recurrent nodules after excision for malignant melanoma, I am not aware of any evidence of its value after mastectomy for breast cancer. In the absence of recurrent disease there would certainly be no indication for any attempt at non-specific enhancement of immunity in the patient. In the event of local recurrence after mastectomy one would hesitate to use an untried technique such as this. Local radiotherapy would be the first line of treatment or, if radiotherapy had already been used as adjuvant treatment after mastectomy, then either hormonal or cytotoxic treatment would be indicated.-HAROLD ELLIS, professor of surgery, London. 